\title{
Neue Elemente und Ephemeride des veränderlichen Sterns Y Cygni.
}

Von N.C. Dunér.

Die auf Grund meiner älteren Elemente von Y Cygni berechneten und in der Vierteljahrsschrift der Astronomischen Gesellschaft mitgetheilten Ephemeriden dieses Sterns fangen jetzt an etwas stark von den Beobachtungen abzuweichen.
Ich habe deshalb, unter Zugrundelegung aller mir bekannten Beobachtungen aus den Jahren 1889-96, neue Elemente hergeleitet und habe erhalten:

$$
\begin{aligned}
& \text { Gerade Minima }=1886+343^{\mathrm{d}} \cdot 4799+1 \stackrel{\mathrm{d}}{4982 \mathrm{rg} E} \quad \text { M. Z. Greenw. } \\
& \text { Ungerade Minima }=1886+343 \stackrel{\mathrm{d}}{3} 39 \mathrm{I} 9+1 \stackrel{\mathrm{d}}{4} 498124 E \text { 》 }
\end{aligned}
$$
gestellt :

Die Normalminima werden in folgender Weise dar-

Gerade Minima.

$\begin{array}{rccrcc}\text { Epoche } & B-R & \text { Bb. } & \begin{array}{r}\text { Epoche } \\ \text { B-R }\end{array} & \text { Bb. } \\ 12 & -0.019 & 5 & 191 & +0.002 & \text { I I } \\ 418 & +0.021 & 4 & 705 & +0.011 & 17 \\ 952 & (-0.094) & 4 & 1187 & -0.003 & 13 \\ 1184 & -0.006 & 28 & 1311 & -0.003 & 10 \\ 1640 & +0.027 & 17 & 1649 & -0.061) & 5 \\ 2208 & -0.018 & 8 & 1913 & -0.011 & 3 \\ & & & 2371 & +0.004 & 9\end{array}$

Gerade Minima.
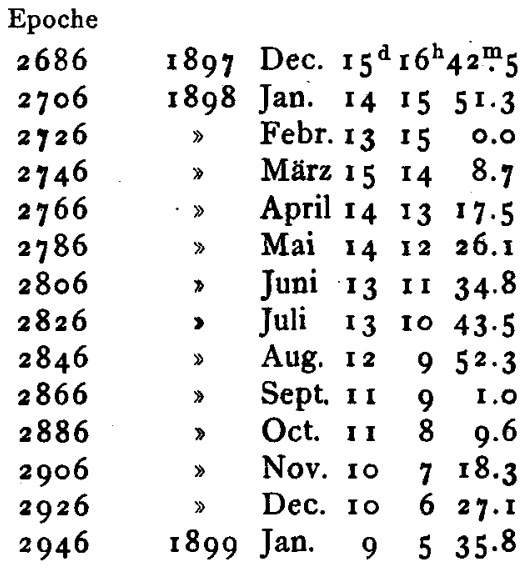

Die Normalminima, mit Ausnahme der geraden Epoche $95^{2}$, die schon bei allen früheren Rechnungen ausgeschlossen werden musste, und eines von den neu hinzugekommenen ungeraden Minima, Epoche 1649 , werden also recht befriedigend dargestellt, und es scheint noch kein Grund vorhanden zu sein, ein vom Quadrat der Zeit abhängiges Glied einzufübren, wenngleich dies wohl in absehbarer Zeit geschehen muss. Es könnte daher erwartet werden, dass vielleicht schon jetzt die geraden Minima früher, die ungeraden später als nach den Formeln eintreffen werden.

Aus obigen Elementen habe ich die folgenden Ephemeriden berechnet.

\begin{tabular}{|c|c|c|c|c|c|}
\hline \multicolumn{6}{|l|}{ Epoche } \\
\hline 2685 & 1897 & Dec. & $13^{d}$ & $20^{h}$ & $30 \stackrel{\mathrm{m}}{0}$ \\
\hline 2705 & 1898 & Jan. & 12 & 19 & $3^{6.9}$ \\
\hline 2725 & 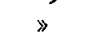 & Febr. & I I & I 8 & 42.9 \\
\hline 2745 & 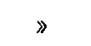 & März & 13 & 17 & 48.9 \\
\hline 2765 & » & April & 12 & 16 & 54.9 \\
\hline 2785 & $»$ & Mai & 12 & 16 & 0.8 \\
\hline 2805 & $»$ & Juni & II & 15 & 6.8 \\
\hline 2825 & » & Juli & I I & 14 & I 2.8 \\
\hline 2845 & 》 & Aug. & IO & 13 & I 8.8 \\
\hline 2865 & » & Sept. & 9 & 12 & 24.7 \\
\hline 2885 & $》$ & Oct. & 9 & I I & 30.6 \\
\hline 2905 &  & Nov. & 8 & 10 & 36.6 \\
\hline 2925 & , & Dec. & 8 & 9 & 42.6 \\
\hline 2945 & I 899 & Jan. & 7 & 8 & 48.6 \\
\hline
\end{tabular}

Ungerade Minima.

Multipla der Perioden.

$$
\begin{aligned}
& 2^{\mathrm{p}}=2^{\mathrm{d}} 23^{\mathrm{h}} 54^{\mathrm{m}} \cdot 8 \\
& 4=52349.8 \\
& 6=82344.7 \\
& 8=\text { II } 2339.6 \\
& \text { I0 }=142334.4 \\
& 12=172329.2 \\
& 14=202324.1 \\
& 16=232319.0 \\
& { }_{1} 8=262313.9
\end{aligned}
$$

$$
\begin{aligned}
& 2^{p}=2^{d} 23^{h} 54^{m} \cdot 5 \\
& 4=52349.2 \\
& 6=82343.7 \\
& 8=112338.4 \\
& 10=142332.9 \\
& 12=172327.6 \\
& 14=202322.1 \\
& 16=232316.8 \\
& 18=2623 \text { 11.3 }
\end{aligned}
$$

Wie man sieht, sind die Minima, vor allem die geraden, im Jahre 1898 unter sehr günstigen Umständen zu beobachten. Die Ephemeriden gelten für mittlere Zeit Greenwich. 